\title{
Rough Endoplasmic Reticulum
}

National Cancer Institute

\section{Source}

National Cancer Institute. Rough Endoplasmic Reticulum. NCI Thesaurus. Code C13329.

Membrane organelle of eukaryotes that forms sheets and tubules. Contains the receptor for the signal receptor particle and binds ribosomes engaged in translating mRNA for secreted proteins and the majority of transmembrane proteins. Also a site of membrane lipid synthesis. The membrane is very similar to the nuclear outer membrane. The lumen contains a number of proteins that possess the $\mathrm{C}$ terminal signal KDEL. 